\title{
Child Day-Care Centres as Supervisory Authorities? The Control of the Measles Vaccination in Germany Burdens the Trust Relationship Between Centres, Parents and Children
}

\author{
Beate Heeg (Eltern helfen Eltern e.V.), Thomas Strzalka (Dachverband der \\ Elterninitiativen und freien Träger (DEOS) e.V.) and Norbert Bender \\ (Bundesarbeitsgemeinschaft Elterninitiativen (BAGE) e.V.)
}

\begin{abstract}
:
In Germany there have been intense discussions about measles vaccination and, as a consequence, the "Law for the Protection against Measles and for Strengthening Vaccination Prevention (Measles Protection Act)" was passed. The Measles Protection Act has now been in force since 1 March 2020 and has far-reaching consequences for day-care centres for two reasons. First, children and staff in day-care centres must prove that they have been vaccinated against measles before being admitted to the centre. Second, day-care facilities are obliged to notify the local health authority if sufficient proof of measles vaccination is not provided for a child in the day-care facility. This shift in responsibility for the control of the vaccination status poses a great threat to the relationship of trust between parents and educational staff.
\end{abstract}

Keywords:

day-care centres; educational partnership; health authorities; measles; vaccination

The current global coronavirus pandemic demonstrates the importance of vaccination options to control communicable diseases. Last year, this pandemic could not have been foreseen, but in Germany there were intense discussions about measles vaccination and a law was passed to the effect that at least $95 \%$ of all children starting school are immunized by vaccination. This law has now been in force since 1 March 2020 and has far-reaching consequences for day-care centres.

In parents' initiatives, parents organize the care of their children in a day-care centre. The Bundesarbeitsgemeinschaft Elterninitiativen (BAGE) e.V. is an association of 26 advice and contact points for parents' initiatives and would like to present its position in this discussion. The BAGE basically supports the position of the World Health Organization (WHO) to work towards a world without measles and to stem its spread (WHO, 2019), without positioning itself for or against compulsory vaccination in Germany.

\section{The Measles Protection Act}

The Law for the Protection against Measles and for Strengthening Vaccination Prevention (Measles Protection Act) of 10 February 2020 stipulates the following: Before being admitted to the centre, children and staff in day-care centres must prove that they have been vaccinated against measles, either by presenting the vaccination record or a medical certificate. For children from the age of one, proof of one vaccination, for children from the age of two and for employees, proof of two vaccinations must be provided as sufficient protection against measles. This also applies to children who have already been cared for in other institutions (e. g., crèches). Employees, within the meaning of this law, are not only staff, but also volunteers, honorary staff and trainees who work for more than just a few days. Excluded from these regulations are persons with vaccination intolerance or an immunity against measles, which is certified by a doctor. The vaccination requirement also does not apply to employees born before 31 December 1970.

As so-called communal facilities ( $§ 33$ of the Infection Protection Act), day-care centres are obliged to notify the local health authority if sufficient proof of measles vaccination is not provided for a child in the day-care facility, stating the personal data of the persons concerned. According to the wording of the law, this obligation applies to all daycare facilities, including those run by independent organizations. If this notification is not made, made incorrectly, incompletely or not on time, it is an administrative offence and is punishable with a fine of up to $2,500 €$. Of course, fines of this amount are not to be expected immediately after the first infringement. 
Health authorities may carry out their own checks on whether there is sufficient vaccination against measles. If this is the case, the day-care centre is not obliged to notify unvaccinated persons. However, day-care facilities are not allowed to admit children who have not provided proof of sufficient vaccination protection.

\section{Responsibility for Verification of Vaccination Status}

The Measles Protection Act thus shifts the obligation to day-care centres to check whether a measles vaccination has been given. They are required to admit only vaccinated children or children who have to be vaccinated from a certain age. This means that sovereign tasks such as the control of the vaccination status and the withdrawal of a place in a daycare centre (to which every child has a legal entitlement from the age of one), are placed under the responsibility and duty of the management of day-care centres. The law makes it possible for federal states to delegate these tasks to the health authorities rather than to the day-care centres. Unfortunately, and against the background overloaded and under-equipped health authorities, to our knowledge this has not been implemented by any federal state.

We clearly see the responsibility for the control of the vaccination status in places other than day-care centres. The legislator should stipulate that the health authorities must write to the parents of children of vaccination age and if the vaccination is not carried out, a reminder must be sent. This would be an appropriate reaction, assuming that most parents do not refuse the (second) vaccination, but have often simply forgotten about it. In this way the sovereign task of controlling and sanctioning the status of measles vaccination would clearly lie with an appropriate authority. In our opinion, proof of vaccination should also be provided exclusively to public health services or the public health department. Shifting this sovereign task of the health authorities towards users (children and their parents) and employees (educators) to the management of day-care centres is misguided in terms of regulatory policy.

\section{Consequences for Pedagogical Work}

The above-mentioned transfer of responsibility to the day-care centres poses a great threat to the relationship of trust between parents and educational staff. Trust is very important for partnerships in any educational institution.
These relationships are already being put to the test by the coronavirus pandemic. The closure of day-care centres for weeks and months and the associated provision of emergency care for children of parents from specific occupational groups, in some cases led to intense discussions as to which parents may make use of emergency care. Day-care centres were often left alone to make these decisions which naturally generated conflict, especially within parent initiatives. The control of compulsory measles vaccination places an even greater burden on the trust relationship between parents and pedagogical staff. It severely jeopardizes the educational partnership that day-care centres strive for when they admit a child and in some cases, it may make this partnership impossible. In our view, this is not justifiable.

\section{Unresolved Issues}

It is still unclear how to deal with children who are vaccinated when they are admitted to a day-care centre (i.e. at one year of age), but who do not receive a second vaccination later on. According to the law, they are to be reported to the public health department. Would day-care centres ultimately be forced to terminate a care agreement because of a missing compulsory vaccination? In 25 out of 31 other European countries, the second measles vaccination for children aged three years is not even planned for in early childhood (European Centre for Disease Prevention and Control, 2020). It therefore seems all the more absurd to us that children without (the second) measles vaccination in Germany are (should be) excluded from attending a day-care centre.

The law also leaves open how to deal with employees who are required to be vaccinated but are not willing to do so. Ultimately, day-care centres would be forced to give these people notice of termination if the health authorities were to impose a permanent ban on their employment. Furthermore, the law does not clarify how to deal with volunteers. Volunteers (especially parents) are of particular importance to the parents' initiatives in day-care centres.

It must also be clarified that the cost of the personnel and administrative effort for the control and notification of the vaccinations and, above all, the cost of any necessary immunity tests and the necessary vaccination of the employees, will be included in the financing of day-care centres.

\section{References}

European Centre for Disease Prevention and Control. (2020). Measles: Recommended vaccinations. Vaccine Scheduler. https://vaccineschedule.ecdc.europa.eu/Scheduler/ByDisease?SelectedDiseaseId=8\&SelectedCountryIdByDisease=-1

World Health Organization. (2019, December 5). Measles. https://www.who.int/news-room/fact-sheets/detail/measles 


\title{
Recommended Citation
}

Heeg, B., Strzalka, T., \& Bender, N. (2020). Child day-care centres as supervisory authorities? The control of the measles vaccination in Germany burdens the trust relationship between centres, parents and children. On Education. Journal for Research and Debate, 3(8). https://doi.org/10.17899/on_ed.2020.8.7

\begin{abstract}
About the Authors
Beate Heeg is a lawyer and has been with Eltern helfen Eltern e.V. as an operational-organizational expert advice and managing director for 24 years.

Thomas Strzalka is an educator and expert advisor for parent initiatives. He has many years of experience as head and deputy head in small mixed-age parent initiatives and is currently part of the voluntary board of directors at DEOS e.V.

Norbert Bender is an economist and theatre pedagogue as well as a co-founder of one of the first parent initiatives in East Berlin. He has been the managing director of BAGE e.V. for 10 years now.
\end{abstract}

